\title{
Research on the Steering Effect of Online Information upon Tourist flow
}

\author{
Guanghui JIANG \\ Tibet Vocational Technical College, Lhasa Tibet, China 850000
}

Keywords: Steering effect, Online information, Tourist flow, Tourist/travelers, Websites.

\begin{abstract}
Along with the in-depth development of information technology, tourism e-commerce and websites have played an important role in tourism. As the combination of tourism industry with information technology is becoming more and more closely, tourist have become more and more dependent on online tourism information. The steering effect of online information upon tourist flow is mainly embodied in potential tourists' demand for online information and service, as is the main research content of this paper. This demand runs through three stages before potential tourists start real travel, wherein the steering effect of tourism websites on them respectively corresponds to three aspects: (1) travel decision making; (2) tourism information inquiring; and (3) travel booking. The steering effect of online information upon tourist flow is mainly embodied in the three stages. In the first stage, online information has become the main source for tourists for leisure and on vacation. In the second stage, the major reason for which tourists visiting family and friends use websites is inquiring for flight and ticket information while the major motive for which tourists for leisure and on vacation use websites is that they need to learn more information related to the destination. In the third stage, websites gains the most rapid development among all the booking and reserving ways, but their main service is focused on flight booking and hotel reserving.
\end{abstract}

\section{Introduction}

As information is the growing point and the booster of social development, the human society is experiencing a profound change of informatization in all the aspects. Under the dual drive from economic development and scientific and technological progress, network scale has been expanding year by year in China. By the end of June 2011, the scale of Chinese Internet users reached 485 million, and Internet access rate climbed to $36.2 \%$. [1] Tourism is a "sunrise industry" in the new century in that it serves as an important pulse that pushes national and regional economic development. Under the background of informatization, the tourism industry is also popularly favored and its combination with information technology is becoming more and more closely. As tourists have become more and more dependent on online tourism information, the guiding role the latter plays in affecting potential tourists and reals tourists will also become strengthened and intensified.

Since earlier this century, tourism e-commerce and websites have played an important role in the unceasing expansion of the application and impact of information technology in tourism. Specifically, online information and service, especially that provided by tourism websites have exerted all-round influence and omnidirectional effect on potential customers in terms of their travel behavior such as consulting, decision-making, reserving, trip mode, etc. This paper, based on Internet data and index and relevant literature review, focuses on the acting mechanism of how online information exert influence on tourists and their travel behavior and provides a study of the guidance mechanism of online information upon tourist flow.

\section{Literature Review}

Foreign experts have made beneficial explorations into issues concerning the steering effect of intangible information flow on tangible substance flow, e.g. Adams et al. provide a qualitative study of the real effect of Internet on promoting Indian immigrations to the US from the perspective of ICTs, describing a situation wherein information flow steers people flow and highlight the specified path for 
similar research [2]. Scholars at home such as $\mathrm{Lu} \mathrm{Zi}$ et al. propose that the process of information flow steering people flow is carried out by websites with their functionality and service orientation. The steering of online reservation over tourist flow mostly takes the form of international air tours and lodging [3]. Wang Yang et al. summarize four functional platforms, i.e. information, agglomeration, communication and organization platforms with which websites realize the steering function of information flow upon people flow, taking websites outdoor adventure clubs as an example [4]. Many other relevant literature and documents reveal that experts are concerned with the effect of tourism websites on tourist flow from different angles while providing no clarified description of the process and mechanism of tourism websites acting on tourist flow. Therefore, the steering process and mechanism become the main concern of this paper for the following sections.

\section{Steering Effect of Online Information upon Tourist Flow}

The steering effect of online information upon tourist flow is mainly embodied in potential tourists' demand for website information and service, as is the main research content of this paper. This demand runs through three stages before real travel of potential tourists starts, wherein the steering effect of tourism websites on them respectively corresponds to three aspects: (1) travel decision making; (2) tourism information inquiring; and (3) travel booking.

Potential Tourists' Demand for Website Information and Service. Investigations have been made into selected travelers/tourists on the Internet or by interview and relevant data/information have been collected via online searching engines. Nowadays, in the age of information explosion, in particular when individual travel is prevailing all over the world, potential tourists, once in need of travel, will generally get access to the Internet for further understanding of the information about travel destinations and relevant service. The transition from potential tourists into real tourist flow requires going through three stages, i.e. travel decision making, information searching and travel booking. The following analysis will cope with the question as how travel websites exert influence upon tourist flow into terms of their effect in the three stages.

Steering Effect of Tourism Websites on Tourists in the Travel Decision Making Stage. In the decision making stage, travelers tend to be influenced by many information sources including websites, which have been exerting more and more influence upon travelers and their tours than before. In family or friends visiting travel, three major information sources that have greater influence on tourists than the others are: family members' or friends' inhabitation, tourism websites and personal previous travel experience. In leisure or vacation tour, three sources are: tourism websites, travel agencies and personal previous travel experience. The steering effect of tourism websites on tourists in the travel decision making stage is shown in Table 1. Although the websites do not have an overwhelming advantage over the other sources, the effect they exert upon tourists' decision making is becoming more and more prominent according to the information collected from the Internet and both online and offline interviews with the subjects. [5]

Table 1 Effect of Major Travel Information Sources upon Tourists

\begin{tabular}{|l|c|c|}
\hline Major Travel Information Sources & Family/friends visiting travel & Leisure/vacation tour \\
\hline Websites & + & ++ \\
\hline Agencies & \pm & + \\
\hline Books or guides & - & \pm \\
\hline Personal previous travel experience & + & + \\
\hline Family members' or friends' inhabitation & +++ & - \\
\hline Family members' or friends' travel experience & - & - \\
\hline
\end{tabular}

Note: indicator labelled as - signifies less effect, \pm normal, + much, ++ more and +++ most. 
Subsequently, according to the investigation into the factors that have led to the websites' effect upon the tourists' decision making, the most influential one is their credibility. That is, if a website is qualified with these standards like having good publicity, visibility in marketing and reputation, it will get most, if not all of the tourists' favor and vice versa. [6] This reflects, in another angle, that tourism websites vary in development level and degree, in particular, in the larger environment that lacks credibility. Therefore, tourists prefer to more credible and famous websites. Next, the factor ranking the second is characteristics of tourism product. This calls for exploration into tourism consumption groups and subsequent design and development of special recommendations that fit for them. In addition, if a website updates its information more frequently and provides elements with more interactivity, it will affect tourists to a greater degree. However, price, a factor usually considered very important, fails to exert influence upon tourists' decision making. This reveals that tourists are undergoing a transition of focus from on price to on value of tourism products.

Steering Effect of Tourism Websites on Tourists in the Information Searching Stage. Through the first stage, after making decision potential tourists are going look for more and detailed information about their expected travel destination. However, the effect of tourism websites on family or friends visiting travel is largely different from that on leisure or vacation tour. The major reason for which tourists visiting family members or friends use these websites is to search for information about airlines and thickets. This indicates that these tourists, who have a clear purpose, namely, visiting their family members or friends, care most the achievement of their travel. On the contrary, the tourists for leisure or on vacation use these websites to look for more and detailed information about their travel destination, thus helping themselves to form a comprehensive impression about the destination and to be more acquainted with it, so that they can smoothly carry out travel activities. In addition, travelers for leisure or on vacation exhibit a higher proportion than those visiting family members or friends in using tourism websites for searching for lodging information, looking for information that can help them to design traveling routs and getting information about recent big events, festivals and celebrations or in the near future. It is noteworthy that the proportion of the tourists that use tourism websites to help to plan traveling routs and to get the traffic information about the destination is far larger than that of those who use the websites to look for travel agencies. This phenomenon reveals, to a great extent, that independent travel, self-guided tour or DIY tour has become more prominent day by day. [7] Therefore, travel service and tourist agencies should pay more attention to the change of modes of traveling and work out corresponding countermeasures. (Details are shown in Table 2.)

Table 2 Tourists' Reasons for Using Tourism Websites

\begin{tabular}{|l|l|l|}
\hline Reasons for using tourism websites & Family/friends visiting travel & Leisure/vacation tour \\
\hline $\begin{array}{l}\text { For various relevant information about the } \\
\text { destination }\end{array}$ & + & +++ \\
\hline For lodging inforamtion & \pm & ++ \\
\hline For planning travel rout & + & + \\
\hline For traffic information of the destination & + & + \\
\hline For big events, festivals and/or celebrations & \pm & + \\
\hline For airline and/or ticket information & +++ & \pm \\
\hline For travel service and tourist agencies & - & - \\
\hline For others & - & - \\
\hline
\end{tabular}

Note: Indicator labelled as - signifies less effect, \pm normal, + much, ++ more and +++ most.

Steering Effect of Tourism Websites on Tourists in the Travel Booking Stage. In the travel booking stage, there is no big difference between the two tourist flow in that both tourists for leisure or on vacation and for family or friends visiting need displacement to the destinations eventually 
while the major approach to realize the displacement is booking flights, as shown in Table 3 . In so far as lodging during the travel is concerned, there is slight difference. Most tourists for visiting family members or friends, perhaps because their accommodation problem has been settled with the help of their family or friends, display a lower rate in reserving hotels than tourist for leisure or on vacation, as shown in Table 4.

By the end of 2012, the most frequent method tourists use to reserve hotels is telephoning, which has been presenting a downwards trend since 2009. [8] The reserving methods ranking the second and third are interpersonal activity and using websites respectively. The use of websites has gained the most rapid increase, but its effect upon tourists is still relatively restricted in this stage. Two main causes are identified through the analysis. Firstly, flight booking and hotel reservation are the two major areas found with tourists' online applications while booking or reserving actions are confronted with slow development in the other areas. Secondly, travel booking involves cooperation of distinct domains as well as integration of resources such as information technology, banking, finance, etc. This phenomenon reflects that tourism agencies, lacking innovation competence and resources integration ability, provide restricted and homogeneous online booking and reserving service and are confronted with confinement in developing online booking and reserving.

Table 3 Major Ways to Book and Reserve

\begin{tabular}{|l|l|l|}
\hline Major Ways to Book and Reserve & Family/friends visiting travel & Leisure/vacation tour \\
\hline Telephones & +++ & +++ \\
\hline Interpersonal relationship & ++ & ++ \\
\hline Websites & + & + \\
\hline
\end{tabular}

Note: indicator labeled as +++ signifies most frequent use, ++ more frequent and + frequent.

Table 4 Major Domains of Booking and Reserving

\begin{tabular}{|l|l|l|}
\hline Major Domains of Booking and Reserving & Family/friends visiting travel & Leisure/vacation tour \\
\hline Flights or tickets & +++ & +++ \\
\hline Hotels and accommodations & \pm & ++ \\
\hline Others & - & - \\
\hline
\end{tabular}

Note: indicator labeled as +++ signifies most prominent, ++ more prominent, \pm normal and not prominent.

\section{Summary}

As the combination of tourism industry with information technology is becoming more and more closely, tourist have become more and more dependent on online tourism information. Tourists' demand for online information and service runs through three stages before potential tourists start real travel, to which the steering effect of tourism websites on them respectively corresponds. The steering effect of online information upon tourist flow is mainly embodied in the three stages, namely, decision making, information inquiring and booking or reserving stages. In the first stage, online information has become the main source for tourists for leisure and on vacation. In the second stage, the major reason for which tourists visiting family and friends use websites is inquiring for flight and 
ticket information while the major motive for which tourists for leisure and on vacation use websites is that they need to learn more information related to the destination. In the third stage, websites gains the most rapid development among all the booking and reserving ways, but their main service is focused on flight booking and hotel reserving. This paper has made an attempt at analyzing the steering effect of online information upon tourist flow and hope to be helpful for tourism websites construction as well tourism development planning.

\section{Author in brief}

JIANG Guanghui, of Dong minority, born in Miao-Dong Autonomous Prefecture of Qiandongnan of Guizhou province in 1984, master of tourism management, lecturer and young and middle-aged backbone teacher at Tibet Vocational Technical College, whose research direction is regional tourism economy, tourism planning, etc.

\section{References}

[1] L. K. Liu, Z. Lu, On the integration of website information flow and its guidance for people flow, Information Science. 4, 25 (2007) 511-516.

[2] P. Adams, R. Ghose, The construction of a space between India, Progress in Human Geography. 4, 27 (2003) 414-437.

[3] Z. Lu, Z. P. Deng, Y. Wang, A case based research on the directive function of website intelligence to human flow, in: Applied Artificial Intelligence, 2006, pp. 485-492.

[4] S. Li, R. X. Qiu, L. Chen, Cyber attention of tourist attraction based on Baidu Index: temporal distribution and precursor effect, Geography and Geo-Information Science. 6, 24 (2008) 102-107.

[5] G. M. S. Dann, Anomie, ego-enhancement and tourism, Annals of Tourism Research. 4, 4 (1977) 184-194.

[6] J. L. Crompton, Motivations for pleasure vacations, Annals of Tourism Research. 4, 6 (1979) 408-424.

[7] S, Yuan, M. Cary, Motivational determinants of international pleasure Time, Journal of Travel Research. 1, 24 (1990) 42-44.

[8] J. Gnoth, Tourism motivation and expectation formation, Annals of Tourism Research. 2, 24 (1997) 283-304. 